\title{
Pilot-scale Culture of adventitious Root for the Production of pharmacology active from medicinal plants: a Mini Review
}

\author{
Thanh-Tam $\mathrm{Ho}^{1,2^{*}}$, Thi My Ngan $\mathrm{Ha}^{3}$, Thi Kim Cuc Nguyen ${ }^{4}$, and Thanh Do Le $\mathrm{Le}^{1,2}$ \\ ${ }^{1}$ Institute for Global Health Innovations, Duy Tan University, Da Nang, 550000, Viet Nam \\ ${ }^{2}$ Duy Tan University, Da Nang, 550000, Viet Nam \\ ${ }^{3}$ VNUHCM-University of Science, Ho Chi Minh, Viet Nam \\ ${ }^{4}$ Hue University, Road 10, Phu Thuong, Phu Vang, Thua Thien Hue, Viet Nam
}

\begin{abstract}
Plant tissue culture technology is a technique for aseptic culture of plant tissues under artificial culture conditions. It can be used as a means to directly mass-produce of bioactive compounds from different culture systems such as adventitious roots (ARs), hairy root, callus, somatic embryogenesis of medicinal plants. ARs cultures show high root proliferation, biomass production and have the potential to synthesize specific bioactive compounds. ARs can be induced in vitro from various explants, such as leaves, roots, stem, petiole callus, etc. Various parameters such as auxins, nitrous oxide, and light have shown to affect the morphogenesis of ARs. Air-lift bioreactors appear to be ideal for plant cell and organ cultures. They are suitable for the ARs culture of various medicinal plants. To scale-up ARs cultures, the Balloon type bubble bioreactor (BTBB) is reported to be a suitable system for the accumulation of both biomass and bioactive compounds production in numerous various medicinal plants. BTBB provides optimum conditions for growth and bioactive compound accumulation by efficiently controlling the culture environment, foam generation, reducing shear stress, and supplying optimal oxygen. This review summarized a strategy and approach for ARs culture for the production of biomass and secondary metabolites from laboratory to industrial scales by using air-lift bioreactor culture systems.

Keywords: adventitious root culture, bioactive compounds, biomass, bioreactor, medicinal plant,
\end{abstract}

\section{Introduction}

Plants have been an integral part of traditional medicines system around the globe. The overall world herbal trade was assessed to be US\$ 120 billion in 2015 and expected to grow up to US\$ 7 trillion by 2050 (NMPB, 2016). However, the dwindling natural resources and growing consumer-driven demand for natural compounds putting undue pressure on manufacturer to look for alternative mechanism to get quality raw material. In recent years, as pharmaceuticals and pharmaceuticals using a single component have been developed, the

\footnotetext{
* Corresponding author: hothanhtam2@duytan.edu.vn
} 
supply of qualified homogeneous ingredients has become very important $[1,2]$. Considering the market status and industrial demands, the production of these bioactive compounds at an industrial scale by in vitro biotechnological approaches could be the best strategy $[2,3]$.

Currently, the technique of plant cells, tissues, and organs culture is considered as an alternative tool for plants to produce attractive secondary compounds. In particular, the methods for ARs roots culture are considered effective methods for the production of biomass and bioactive compounds. ARs are attractive source of phytochemicals due to their genetic and biosynthetic stability [2,3]. However, not all sources of the active substance in field-grown are well developed and high level of bioactive synthesized in vitro. It depends on specific plants, specific compounds, genotypes as well as in vitro culture conditions. In recent years, various strategies have been developed for enhancing of biomass production and bioactive compounds accumulation in plant cell and organ culture [3,4]. Biomass production and bioactive compounds biosynthesis are two-stage of process. First stage controlled the parameter assist with the growth and biomass production of cells and organ culture. The parameters that assist with bioactive compound biosynthesis were controlled at second stage. Figure 1 summarized process for developing ARs culture for the production of biomass and bioactive compounds from laboratory to industrial scales by using air-lift bioreactor culture systems.

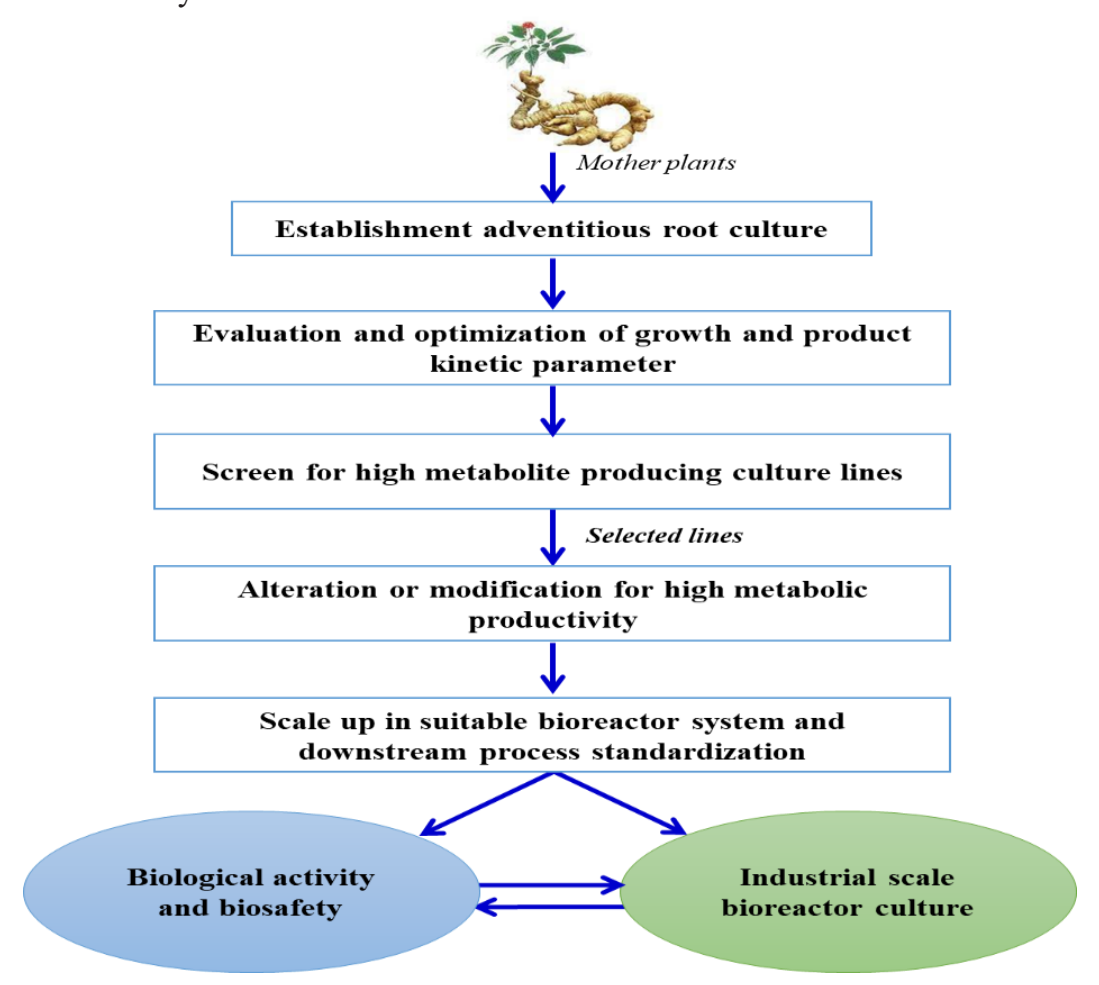

Fig.1. Scheme diagram for adventitious culture process from laboratory to industrial scales.

\section{Adventitious root cultures for biomass and bioactive compounds production in medicinal plants}

ARs can be induced in vitro from various explants, such as leaves, roots, stem, petiole, hypocotyl, cotyledon, callus, etc. Basically, the adventitious roots are of endogenous origin, due to auxin-induced dedifferentiation of parenchymal cells surrounding the vascular tissue 
system. However, only certain cells such as parenchymal libe cells of meristem are able to differentiate into root primordia. Various parameters such as auxins, nitrous oxide, and light have shown to affect the morphogenesis of adventitious roots [5,6]. ARs cultures are successfully applied for bioactive production in numerous medicinal plant such as Panax ginseng [1,2], Withania somnifera [7], Panax vietnamensis [8], Oplopanax elatus, etc [9].

In ARs culture, several factors for optimization culture medium such as plant growth regulator levels; suitable medium salt strength, sugar, nitrogen, phosphate, and physical factors such as temperature, illumination, light quality, medium $\mathrm{pH}$, agitation, aeration, and environmental gas (e.g., oxygen, carbon dioxide, and ethylene) are controlled $[1,10]$. In particularly, the inoculum density is a key factor that affects the overall biomass yield and accumulation of bioactive compounds under in vitro culture conditions [9,11,12]. High initial inoculum was using in cell suspension culture as there is a minimum inoculation density below which growth does not occur by a lag phase [13]. However, earlier reports on ARs cultures of Scoplia parviflora suggested that high inoculum density negatively affected the accumulation of scopolamine [14]. The low bioactive compounds accumulation in ARs culture with high initial inoculum density in Hypericum perforatum and Echinacea angustifolia were obtained $[15,16]$. On the other hand, culture periods are the factors for endorsement of bioactive compounds synthesis [17]. The culture began at the lag phase, and it was followed by accelerated growth in the log phase, and then stable phase, thereafter continuous decline in root biomass yield. Bioactive compounds productivity is one of the crucial parameters for determining the optimal culture period.

\section{Elicitation for enhancing bioactive compounds accumulation}

Although, optimization of process parameters can lead to an enhancement of biomass and bioactive compounds production, the major obstacles in this stage are low product yield and fail to produce the target product $[1,18]$. Thus, in the second stage of biomass production and bioactive compounds biosynthesis, the strategies to enhance the production of desired metabolites must be considered [19]. In this case, several techniques have been adopted to improve secondary metabolites such as elicitation, precursor feeding, replenishment of nutrient, etc. Among various biotechnological approaches, elicitor is the most popular to use. Elicitation is an effective tool for improving the biosynthesis of secondary metabolites [20]. Furthermore, a number of studies have employed plant defense mechanisms using elicitors to increase the yields of secondary metabolites under in vitro conditions [21]. Depending on their nature or form, elicitors can be primarily grouped into biotic such as yeast extract (YE), chitosan $(\mathrm{CH})$, bacteria and fungal extract, etc., and abiotic such as methyl jasmonate (MJ), salicylic acid (SA), and metal nanoparticles (NP), etc. Elicitation is seen as an effective strategy for enhancing production of important bioactive compounds such as withanolide [7], ginsenosides [11], anthraquinones [22], tanshinone [23], solasodine [24], and Polygonum multiflorum [25].

\section{Applied bioreactors system for production of biomass and bioactive compounds from adventitious root culture}

Translating the laboratory scale production designs into large scale production is the major challenge in the production of phytochemicals from cell or root culture [1-3]. Airlift bioreactors appear to be ideal for plant cell and organ cultures. They are suitable for the cultivation of ARs of various medicinal plants (Table 1). To scale-up ARs cultures, the Balloon-type bubble bioreactor (BTBB) (Fig. 2) is reported to be a suitable system compared to bulb-, cone-, cylinder- type bioreactor for the accumulation of both biomass 
and bioactive compounds production in numerous various medicinal plants $[1,2,26]$. BTBB provides optimum conditions for growth and bioactive compound accumulation by efficiently controlling the culture environment, foam generation, reducing shear stress, and supplying optimal oxygen $[1,2,10]$.

Table 1. Adventitious root cultures in bioreactors system of some medicinal plants

\begin{tabular}{|c|c|c|c|c|c|}
\hline No. & Plant species & $\begin{array}{l}\text { Bioreactor- } \\
\text { type }\end{array}$ & $\begin{array}{c}\text { Volume } \\
\text { (L) }\end{array}$ & $\begin{array}{c}\text { Bioactive } \\
\text { compounds }\end{array}$ & References \\
\hline 1 & Morinda citrifolia & BTBB & 3 & Anthraquinones & {$[1,22]$} \\
\hline 2 & Panax ginseng & BTBB & 3,5 & Ginsenosides & {$[2,11]$,} \\
\hline 3 & Olopanax elatus & BTBB & 5 & $\begin{array}{c}\text { Phenolics, flavonoids, } \\
\text { polysaccharides, }\end{array}$ & {$[9,29]$} \\
\hline 4 & Hypericum perforatum & BTBB & 3,5 & $\begin{array}{c}\text { Phenolics, flavonoids, } \\
\text { chlorogenic acid, } \\
\text { hypericin }\end{array}$ & {$[15,32]$} \\
\hline 5 & Echinacea angustifolia & BTBB & 5 & $\begin{array}{c}\text { Caffeic acid } \\
\text { derivatives }\end{array}$ & {$[16,26]$} \\
\hline 6 & Echinacea purpurea & BTBB & 5 & $\begin{array}{c}\text { Caffeic acid } \\
\text { derivatives }\end{array}$ & [19] \\
\hline 7 & Polygonum multiflorum & BTBB & 3 & $\begin{array}{c}\text { Phenolics, flavonoids, } \\
\text { anthraquinones }\end{array}$ & {$[25,31]$} \\
\hline 8 & Eurycoma longifolia & $\begin{array}{c}\text { Bubble } \\
\text { column } \\
\text { bioreactor }\end{array}$ & 5 & $\begin{array}{l}\text { Eurycomanone, } \\
\text { polysaccharides }\end{array}$ & {$[27]$} \\
\hline 9 & $\begin{array}{c}\text { Eleutherococcus } \\
\text { koreanaum }\end{array}$ & ВТВB & 3,20 & Eleutherosides & {$[28]$} \\
\hline
\end{tabular}

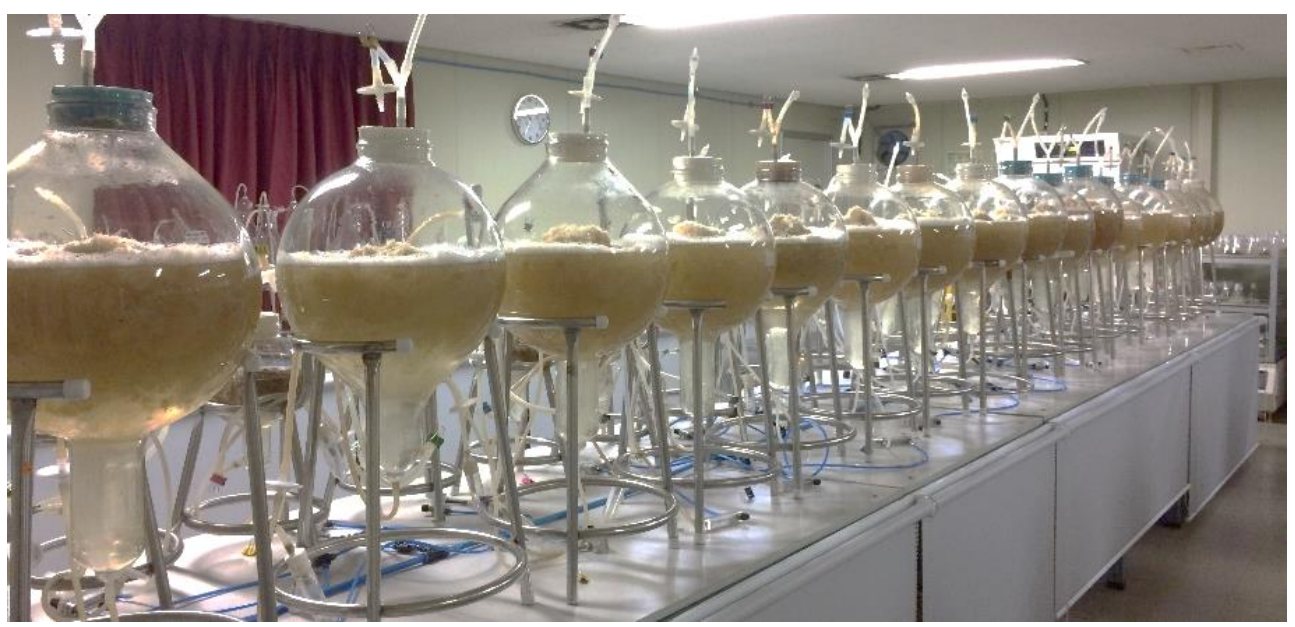

Fig. 2. Adventitious root culture in bioreactor system for the production of pharmacology active

During bioreactor culture, many parameters such as including culture medium (medium salt strength, sucrose concentration, auxin concentration), inoculation density, culture period, elicitation, and aeration rate, etc. which affected the culture's biomass and metabolite production have been widely discussed [2,10,27]. Inoculation density and aeration rate are critical control parameters. At a low inoculation density, cultures cannot fully absorb nutrients, and the time to reach maximum growth is prolonged because of the 
decreased growth rate, thereby reducing the equipment utilization; at a high inoculation density, cultures compete for limited nutrients, leading to a decrease in biomass and metabolite accumulation. In addition, the poor heat and mass transfer in the bioreactor affects the nutrient absorption of cultures under the condition of low aeration. However, under high aeration, oxidative stress is easy to cause damage to cultures [2,10]. Biomass production significantly increases with increasing bioreactor volume, but the culture conditions (both chemical and physical factors) should be adjusted to culture species, explant type, and cultural objectives.

In bioreactor culture, the first step involves the optimization of root growth in bioreactors without elicitor and then concentration and time of elicitor application will have to be standardized in the second step [2,25]. Numerous studies have been reported in using balloon-type bubble bioreactor (BTBB) for both biomass production and enhancement of secondary metabolite treated with elicitors. The addition of $50 \mu \mathrm{M}$ MJ for 1 week was found to be the optimal concentration for eleutheroside B and E, and chlorogenic acid production in adventitious root culture of Eleutherococcus koreanum [28]. Jiang et al. (2017) reported that when added $200 \mu \mathrm{M}$ MJ to culture medium after 30 days of culture, maximum productivity of bioactive compound was found 8 days after treatment in the ARs cultures of Olopanax elatus [29]. Baque et al. (2012) achieved the highest accumulation of secondary metabolites in Morinda citriflora adventitious root cultures and cultures which were treated with $100 \mu \mathrm{M}$ MJ after 4 weeks of culture [1]. Similarly, $100 \mu \mathrm{M}$ MJ was also the highest ginsenoside accumulation in Panax ginseng [2].

Furthermore, after controlling for the factors affecting biomass and bioactive compounds accumulation, ARs can be grown extensively in larg-scale bioreactor systems. The ARs cultures of a few medicinal plant species have been successfully scaled up from 500 to $10,000 \mathrm{~L}$ in industrial bioreactors [1, 2]. In pilot scale, producing 1000-1300 $\mathrm{kg}$ fresh weight of Panax ginseng adventitious root in a 10-ton bioreactor with approximately 10 $12 \%$ root dry weight was successful developed [30]. In addition, the adventitious roots were successfully applied for large-scale (500 L-2000 L) production of biomass and bioactive compounds in several plants such as Morinda citriflora [1], Echinacea purpurea [1, 19], Echinacea angustifolia [1,26], Polygonum multiflorum [31], Hypericum perforatum [32].

\section{Conclusion}

The advancement in the adventitious root of research has made an attractive alternative to natural plant cultivation for the production of pharmacologically active compounds. The results have also demonstrated that bioreactors are a suitable technology for the large-scale culture of adventitious roots of various medicinal plants. These results are premise for biomass and bioactive compounds production of medicinal plants in bioreactor systems on a commercial scale, provide potential material for the pharmaceutical, cosmetics, functional food industry.

\section{References}

1. M.A. Baque, S.H. Moh, E.J. Lee, J.J. Zhong, K.Y. Paek, Biotechnol. Adv. 30:1255-1267 (2012)

2. H.N. Murthy, V.S. Dandin, K.Y. Paek. Phytochem. Rev. 15 (2016)

3. T.T. Ho, H.N. Murthy, D. Dalawai, M.A. Bhat, K.Y. Paek, S.Y. Park, Appl. Microbiol. Biotechnol. 103, 8 (2019)

4. T.T. Ho, C.S. Jeong, L. Hyoshin, S.Y. Park, Plant Cell Tiss. Org. Cult. 137 (2019)

5. Y.S. Kim, E.J. Hahn, E.C. Yeung, K.Y. Paek, In Vitro Cell Dev. Biol-Pl. 39 (2003)

6. M.A. Baque, EJ. Hahn, K.Y. Paek, In Vitro Cell Dev Biol-Pl. 46(2010). 
7. N. Praveen, H.N. Murthy In: K.Y. Paek, H.N. Murthy, J.J. Zhong (eds.) Production of biomass and bioactive compounds using bioreactor technology. Springer, Dordrecht, pp 285-316 (2014)

8. N.T.N. Linh, L.K. Cuong, H.T. Tam, H.T. Tung, V.Q. Luan, V.T. Hien, N.H. Loc, D.T. Nhut, Plant Cell Tiss. Org. Cult. 137 (2019)

9. Y.J. Jiang, X.C. Piao, J.S. Liu, J.. Jiang, Z.X. Lian, M.J. Kim, M.L. Lian, Plant Cell Tiss. Org. Cult. 123 (2015)

10. H.N. Murthy, E.J. Lee, K.Y. Paek, Plant Cell Tiss Org. Cult. 118 (2014)

11. K.Y. Paek, H.N. Murthy, E.J. Hahn, J.J. Zhong, Adv. Biochem. Eng. Biotechnol. 113 (2009)

12. J. Devi, R. Kumar, K. Singh, A. Gehlot, S. Bhushan, S. Kumar, Crit Rev Biotechnol 41 (2021)

13. N.T. Thanh, H.N. Murthy, K.Y. Paek, Ind. Crop. Prod. 60 (2014)

14. J.Y. Min, H.Y. Jung, S.M. Kang, Y.D. Kim, Y.M. Kang, D.J. Park, D.T. Prasad, M.S. Choi, Bioresour. Technol. 98 (2007)

15. S.Q. Wu, X.K. Yu, M.L. Lian, S.Y. Park, X.C. Piao, Acta Physiol. Plant. 36 (2014)

16. C.H. Wu, Y.H. Dewir, E.J. Hahn, K.Y. Paek, J. Plant Biol. 49 (2006)

17. A. Vasconsuelo, R. Boland, Plant Sci. 172 (2007)

18. X. Zhou, J.J. Zhong, Encyclopedia Ind. Biotechnol. 6 (2010)

19. J.A. Jeong, C.H. Wu, H.N. Murthy, E.J. Hahn, K..Y Paek, Biotechnol. Bioprocess. Eng. 14 (2009)

20. R. Radman, T. Saez, C. Bucke, T. Keshavarz, Biotechnol. Appl. Bioc. 37 (2003)

21. J. Zhao, L.C. Davis, R. Verpoorte. Biotechnol. Adv. 23 (2005)

22. P. Komaraiah, P.B.K. Kishor, M. Carlsson, K.E, Magnusson, C.F. Mandenius, Plant Sci. 168 (2005)

23. J.L. Zhao, L.G. Zhou, J.Y. Wu, Appl. Microbiol. Biotechnol. 87 (2010)

24. J. Shilpha, L. Satish, M. Kavikkuil, M.J.V. Largia, M. Ramesh, Ind. Crop. Prod. 71 (2015)

25. T.T. Ho, J.D. Lee, C.S. Jeong, K.Y. Paek, S.Y. Park, Appl. Microbiol. Biotechnol. 102(1) (2018)

26. H.Y. Cui, M.A. Baque, E.J. Lee, K.Y. Paek, Plant Biotechnol. Rep. 7 (2013)

27. M.Z. Fan, X.L. An, X.H. Cui, X.L. Jiang, X.C. Piao, M.Y. Jin, M.L. Lian, Biochem. Eng. J. 171, 108013 (2021)

28. E.J. Lee, S.Y. Park, K.Y. Paek, Plant Cell Tissl Org. Cult. 120 (2015)

29. X.L. Jiang, X.C. Piao, R. Gao, M.Y. Jin, J. Jiang, X.H. Jin, M.L. Lian, Acta Physiol. Plant. 39, 22643 (2017)

30. S.Y. Park, K.Y. Paek. In: K.Y. Paek, H.N. Murthy, J.J. Zhong (eds.) Production of biomass and bioactive compounds using bioreactor technology. Springer, Dordrecht, pp 337-368 (2014)

31. T.T. Ho, K.J. Lee, J.D. Lee, S. Bhushan, K.Y. Paek, S.Y. Park,. Plant Cell Tiss. Org. Cult. 130 (2017)

32. X.H. Cui, H.N. Murthy, K.Y. Paek. Appl. Biochem. Biotechnol. 174 (2014) 